\title{
Application of Electrical Resistivity Tomography for Detecting Root Biomass in Coffee Trees
}

\author{
Carlos Mauricio Paglis \\ Department of Agriculture, Federal University of Lavras, 37200-000 Lavras, MG, Brazil \\ Correspondence should be addressed to Carlos Mauricio Paglis; paglismau@dag.ufla.br
}

Received 15 August 2013; Accepted 21 October 2013

Academic Editor: Jean-Pierre Burg

Copyright ( 2013 Carlos Mauricio Paglis. This is an open access article distributed under the Creative Commons Attribution License, which permits unrestricted use, distribution, and reproduction in any medium, provided the original work is properly cited.

\begin{abstract}
Roots play an important role in plants and are responsible for several functions; among them are anchorage and nutrient and water absorption. Several methodologies are being tested and used to study plant root systems in order to avoid destructive root sampling. Electrical resistivity tomography is among these methodologies. The aim of this preliminary study was to use electrical resistivity for detecting root biomass in coffee trees. Measurements were performed in a soil transect with an ABM AL 48-b resistivimeter with a pole-dipole configuration. The tomograms indicated variability in soil resistivity values ranging from 120 to $1400 \Omega \cdot \mathrm{m}^{-1}$. At the first $0.30 \mathrm{~cm}$ soil layer, these values were between 267 and $952 \Omega \cdot \mathrm{m}^{-1}$. Oriented by this result, root samples were taken at $0.10,0.20$, and $0.30 \mathrm{~m}$ depths within $0.50 \mathrm{~m}$ intervals along the soil transect to compare soil resistivity with root mass density (RMD). RMD data, up to this depth, varied from 0.000019 to $0.009469 \mathrm{Mg} \cdot \mathrm{m}^{-3}$, showing high spatial variability and significant relationship to the observed values of soil resistivity. These preliminary results showed that the electrical resistivity tomography can contribute to root biomass studies in coffee plants; however, more experiments are necessary to confirm the found results in Brazil coffee plantations.
\end{abstract}

\section{Introduction}

Roots play an important role in plants and are responsible for several functions, which include anchorage, acquisition of soil-based resources, storage, synthesis of growth substances, source of organic materials, propagation, and others [1].

Root research under natural conditions is very labor intensive and time consuming. Several methods related to root studies were described in the literature, and these include destructive and nondestructive sampling [2]. Among them one can cite excavation, monolith, auger, profile wall, container, and others $[2,3]$. Most of them are destructive, which prevents future measurements at same location, and require separation of the roots from the soil, commonly by washing. Other more sophisticated methodologies, classified as nondestructive sampling, involve root studies using glass wall, rhizotrons, minirhizotrons [4], and video and digital cameras [2]. In this case, image analysis helps to evaluate roots behavior and allows the researcher to return to the same location for new data collection.

New high technologies of root research can also help avoid destructive sampling and allowing an intensive root study in a new way. Several methodologies were tested such as ground-penetrating radar [5-8], X-ray imaging $[9,10]$, magnetic resonance [11], and electrical and seismic methods [12-15].

The use of electrical resistivity tomography is among these techniques, and its use has been documented by several authors in trees, herbaceous plants, and orchards [12-14, 16-18]. It consists in applying electrical current to the soil through conductors (electrodes) and measuring the resulting differences in electric potential (voltage) at selected positions in the soil. Considering that roots can affect this difference in electrical potential, it is possible to study spatial variability of root distribution in the soil and even quantify them according to the soil resistivity values. The electrical resistivity $(\rho, \Omega \cdot \mathrm{m})$, a measure of the ability of a body to limit the transfer of electrical current, is defined in cylindrical geometry as

$$
\rho=\frac{R \cdot S}{L}
$$

where, $R$ is electrical resistance $(\Omega), S$ is cross-sectional area of the cylinder $\left(\mathrm{m}^{2}\right)$, and $L$ is the length of the cylinder (m). Soil resistivity surveys are conducted by applying 


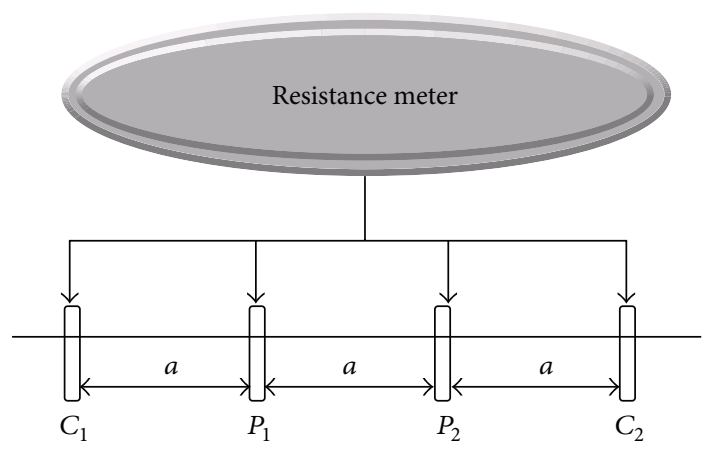

FIGURE 1: Schematic showing the electrical resistivity method with an array of four electrodes: two current electrodes $\left(C_{1}\right.$ and $\left.C_{2}\right)$ and two potential electrodes $\left(P_{1}\right.$ and $\left.P_{2}\right)$. From [16], modified.

electric currents to the soil through conductors (electrodes) and measuring the resulting differences in electric potential (voltage) at selected positions in the soil (Figure 1). The distribution in space of voltage differences is a function of the different resistivity of soil volumes [19]. Traditional electrical exploration aims to make qualitative determinations based on the contrast between soil layers, or between the soil matrix and local heterogeneities, deposits, and intrusions of different materials.

Point measurements of soil resistivity require four electrodes (a quadrupole), two for the injection of electric currents (current electrodes) and two for the measurement of differences in electrical potential (potential electrodes). Electrodes may be arranged in different configurations with potential electrodes placed between current electrodes (as in the Wenner or in the Wenner-Schlumberger configurations) or consecutive to them (as in the Pole-pole or Dipole-dipole configuration). The effects of electrode configuration on resolution, sensitivity and depth of the investigation have been reviewed by Samouëlian et al. [20]. In isotropic media, the current flows radially from the current electrodes into the soil and equipotential lines are hemispherical.

Soil resistivity can therefore be calculated from the difference in electrical potential between the potential electrodes as

$$
\rho=K\left(\frac{V}{I}\right)
$$

where $V$ is difference in electrical potential (V), $K$ is a geometrical coefficient, depending on the electrode configuration, and $I$ is current (A). The depth of investigation depends on configuration and spacing between electrodes. Twodimensional (2-D) tomography of the soil medium requires a linear array of electrodes that can be used as current and potential electrodes according to the chosen configuration. The current flow-lines and equipotential distribution vary accordingly. The survey is conducted by measuring resistivity on a single quadrupole of the array at a time. Current injection and voltage recording are moved from one quadrupole to another along the line. All possible quadrupole spacings along the line are used for measurements, starting from the lowest inter-electrode spacing, corresponding to the distance

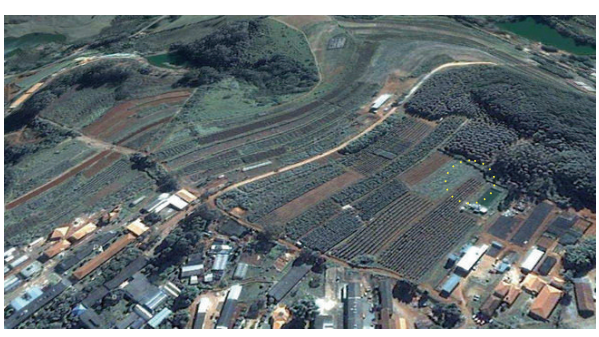

FIgURE 2: Study area location (From Google Earth, modified).

between two adjacent electrodes, to maximum spacing, determined by the total length of the array [20].

In heterogeneous media, the current flow lines are deformed and tend to be concentrated in conductive volumes. Resistivities are first calculated according to the theoretical flow-line distribution in isotropic media and are called "apparent resistivity values." They are attributed to $x$ and $z$ coordinates corresponding to the position along the array $(x)$ and the depth $(z)$ obtained based on the hypothesis of homogeneous current distribution. The 2-D $(x, z)$ section thus obtained is called a pseudosection, and $z$ is called a pseudodepth. Each apparent resistivity value on the pseudo-section corresponds to a soil volume of distorted geometry. One further processing step is needed to obtain the "real resistivity value" and to correctly place it in space. The process is called inversion and requires numerical modeling [21] with soil discretization in elementary cells. Resistivity data are imaged by attributing values corresponding to each elementary soil volume to a point corresponding to the intersection of two lines passing through the centers of the quadrupoles.

The objectives of this research were to access the quantitative relationships between soil electrical resistivity and root biomass and to determine if resistivity tomography could detect the spatial variability of coffee tree root biomass in the field.

\section{Material and Methods}

2.1. Data Acquisition. The aim of this study was to use the $2 \mathrm{D}$ resistivity tomography for detecting root biomass in coffee trees (3-4 years old). The research was conducted at an experimental area located at Federal University of Lavras, Lavras, Minas Gerais, Brazil (Figure 2).

Electrical resistivity measurements were performed in a soil transect under coffee plants. Pole-dipole configuration was used, and measurements were taken $0.25 \mathrm{~m}$ apart by using an ABM AL 48-b resistivimeter (EEG Geofisica, Italy). In total, more than 2700 measurements were taken at 14 different depths up to 2.0 meters. The measured apparentresistivity data sets were inverted by using the RES2DINV software.

In addition, measurements of electrical resistivity were done in a bare soil transect $3 \mathrm{~m}$ away. This was performed to compare soil transects w/o plants and make sure that possible variation in electrical resistivity $(\rho)$ are attributed only to the presence of roots. Figure 3 depicts the electrodes 


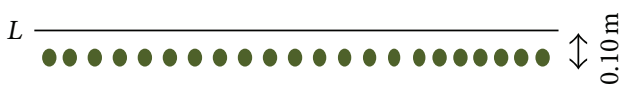

- Coffee trees

Electrode line position

FIGURE 3: Electrodes line position $(L)$ distance to the coffee plants.

line positions along the soil transect, and Figure 4 shows the experimental area and equipment in the field.

2.2. Soil and Roots Sampling. Destructive soil samples were taken to compare soil electrical resistivity with root dry mass per unit of soil volume. The $2 \mathrm{D}$ tomogram indicated a high variability in soil resistivity values in the upper soil layer up to the depth of $0.30 \mathrm{~m}$. Oriented by this soil depth, root samples were taken (at same position of the line electrodes) at $0.50 \mathrm{~m}$ intervals along the transect and at $0.10 \mathrm{~m}$ depth intervals, with a soil corer of $0.05 \mathrm{~m}$ internal diameter, giving a total of 59 samples.

These samples were taken to the laboratory and weighed, and soil gravimetric water content was measured on a $25 \mathrm{~g}$ subsample by weighing before and after drying at $110^{\circ} \mathrm{C}$ to constant mass, obtaining soil dry mass $\left(\mathrm{Dm}_{\mathrm{s}} \mathrm{g}\right)$.

The remaining soil was weighed and washed with a solution of nahexametaphosphate (85\%) and sodium bicarbonate (15\%) at $10 \%(\mathrm{w} / \mathrm{w})$ dilution [22]. Nonroot materials and other soil debris were separated manually and the washed roots were dried in the oven at $65^{\circ} \mathrm{C}$ constant mass to obtain root dry mass $\left(\mathrm{Dm}_{\mathrm{r}} \mathrm{g}\right) . \mathrm{Dm}_{\mathrm{r}}(\mathrm{g})$ was then divided by $\mathrm{Dm}_{\mathrm{s}}(\mathrm{g})$ for each sample and multiplied by the soil bulk density (BD) to give root dry mass per unit soil volume (root mass density, RMD)

$$
\mathrm{RMD}=\left(\frac{\mathrm{Dm}_{\mathrm{r}}}{\mathrm{Dm}_{\mathrm{s}}}\right) * \mathrm{BD} .
$$

2.3. Root and Soil Samples Analysis. Both electrical resistivity $(\rho)$ and root mass density (RMD) values were used to build spatial variability distribution maps along the soil transect. These two maps were obtained by using the mapping software Surfer v.10. In this way, the two maps could be compared to each other.

Basic statistics were applied to the $\rho$, RMD, and soil moisture content $\left(\theta \mathrm{m}^{3} \mathrm{~m}^{-3}\right)$ to determine mean, standard deviation, and maximum and minimum values. Also, several linear regressions were performed to best fit the obtained RMD $\left(\mathrm{Mg} \cdot \mathrm{m}^{-3}\right)$ and the $\rho(\Omega \cdot \mathrm{m})$ data in order to try to explain the potential relationship between them.

The best model found was

$$
\mathrm{RMD}=A+A_{1} \rho^{2.5},
$$

where RMD is root mass density and $\rho$ is electrical resistivity, with parameters $A$ and $A_{1}$ having values of 0.000549 and $2.7913 e-10$, respectively.
TABLE 1: Soil properties from destructive samples.

\begin{tabular}{lccc}
\hline & $\rho(\Omega \cdot \mathrm{m})$ & $\mathrm{RMD}\left(\mathrm{Mg} \cdot \mathrm{m}^{-3}\right)$ & $\theta\left(\mathrm{m}^{3} \cdot \mathrm{m}^{-3}\right)$ \\
\hline Mean & 509.70 & 0.0025 & 27.825 \\
SD & 152.44 & 0.00175 & 0.965 \\
Minimum & 267.59 & 0.000019 & 25.53 \\
Maximum & 952.39 & 0.009469 & 29.79 \\
\hline
\end{tabular}

$\rho$ : electrical resistivity; RMD: root mass density; $\theta$ : volumetric soil water content; SD: standard deviation.

\section{Results and Discussions}

Soil electrical resistivity $(\rho)$ values ranged from 120 to $1400 \Omega \cdot \mathrm{m}$ along the soil transect to a depth of $2 \mathrm{~m}$ (Figure 5). At the first $0.30 \mathrm{~m}$ soil layer, these values ranged from 267 to $952 \Omega \cdot \mathrm{m}$ (Table 1 ). Yet, root dry mass per unit soil volume (RMD) values at the same depth (Figure 6) ranged from 0.000019 to $0.009469 \mathrm{Mg} \cdot \mathrm{m}^{-3}$ showing high horizontal $(x$ axis) spatial variability (Table 1 ).

The spatial distribution of $\rho$ closely matched the spatial pattern of RMD with highest values found at $0.1-0.3 \mathrm{~m}$ soil layer and low values at deeper layers. In both situations, RMD and $\rho$ high variability are closely related to the upper soil layer (Figures 5 and 6). Values of $\rho$ below $0.4 \mathrm{~m}$ are more related to soil intrinsic characteristics than to presence of roots.

Figure 7, depicts the tomogram for a soil transect without plants. One can see that the spatial variability of $\rho$ does not exist at the top layers along the soil transect.

The regression model between RMD and $\rho$ showed a high significant positive correlation $(P<0.01, n=59)$ with $r^{2}=$ 0.723 (Figure 8).

Values of $\rho$ higher than $700 \Omega \cdot \mathrm{m}$ were related to soil samples containing roots with large diameter which provided a high RMD. This was observed in a few soil samples. The majority of the resistivity values are associated with RMD values ranging from 0.001 to $0.004 \mathrm{Mg} \cdot \mathrm{m}^{-3}$, which correspond to small roots with thin diameters.

However, when the regression between electrical resistivity and soil moisture content was performed, the results showed an inverse relationship, but with low $r^{2}$. Similarly, values of soil moisture content were negatively correlated with RMD, and also with low values of $r^{2}$.

The results show spatial variability in the electrical resistivity along the soil profile, and this variability was more evident at the top layers in the studied transect. The $\rho$ values at deep soil layers were lower when compared to those at the top ones. But this might be more related to intrinsic soil factors, by its natural condition rather than by the presence of roots.

In this research, we also studied soil electrical resistivity in a bare soil transect, and one can see, in the obtained tomogram (Figure 7), that there was no spatial variability of $\rho$ in the top layer. The observed values were extremely low, around $110 \Omega \cdot m$, and were the same for any horizontal and vertical position in this layer. Below that there was variability but following almost the same variation pattern existent in the soil tomogram presented in the Figure 5. So, any disturbance in $\rho$ observed at the top layer could be attributed to the presence of roots. 


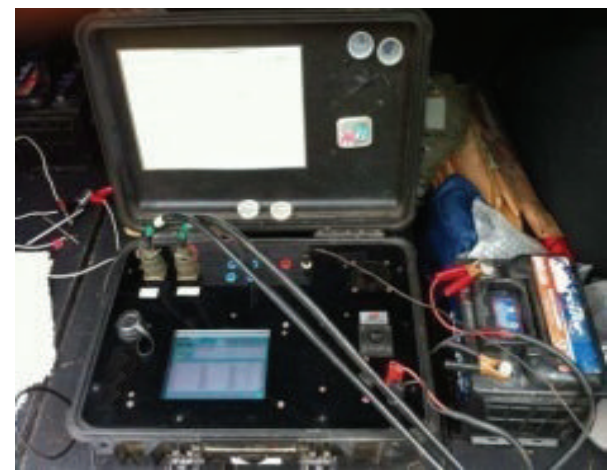

(a)

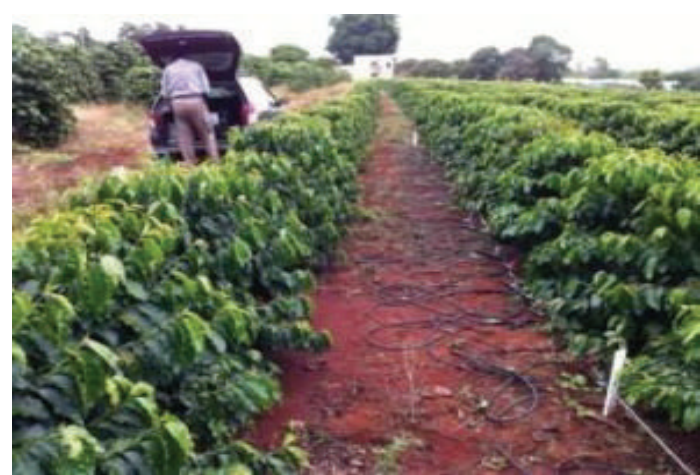

(b)

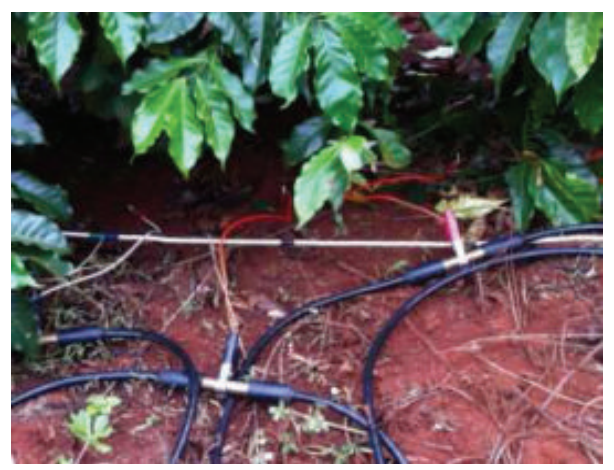

(c)

Figure 4: Photos showing (a) the resistivimeter, (b) coffee plant row, and (c) the electrodes line.

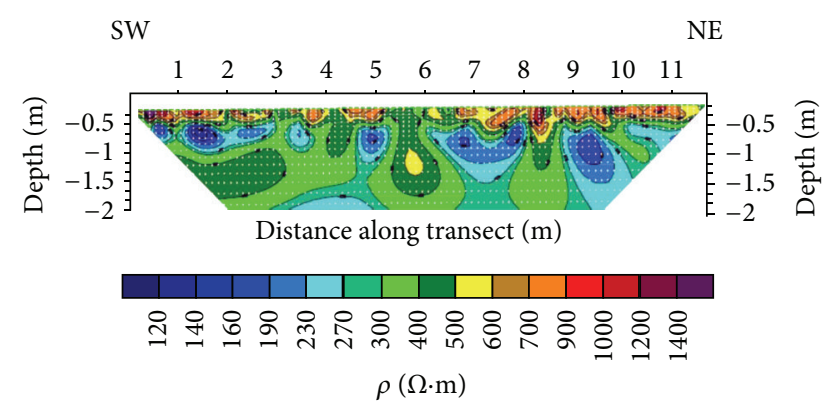

FIGURE 5: Inverted electrical resistivity $(\rho)$ tomogram in area under the presence of coffee tree plants.

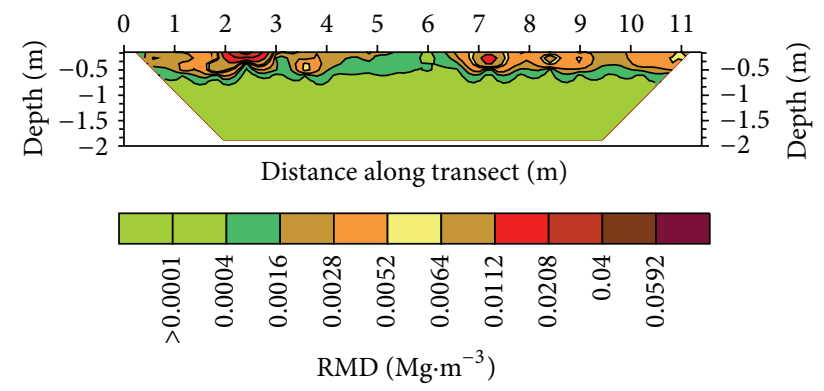

FIGURE 6: Distribution of root dry biomass per unit soil volume (RMD).

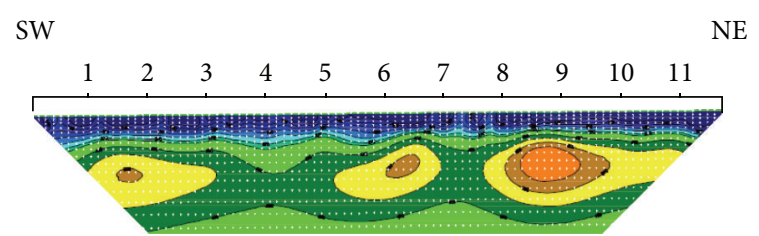

FIgURE 7: Inverted electrical resistivity $(\rho)$ tomogram for calibration.

The obtained $\rho$ tomogram closely matched the horizontal and vertical distribution of the spatial variability of RMD. Roots were more concentrated at top layer of the soil and were clustered in some positions. Soil sampling was not performed below top layer due to the age of the plants and considering that roots, if present, would have extremely low influence on the values of RMD and $\rho$. When the maps of spatial variability of RMD and the $\rho$ tomogram were compared it became evident that the variability of $\rho$ on the soil top layer could be explained by the presence of roots. Our research showed the same tendency observed by other authors. Amato et al. [12] studying the applicability of electrical resistivity tomography in Alnus glutinosa (L) Gaertn stand reported that there was a positive correlation between $\rho$ and RMD and that a high proportion of the variability in soil resistivity was explained by the root density. These results were also found at the $0.30 \mathrm{~m}$ soil depth. Similar results were observed in studies involving herbaceous plants. In this case, plant roots were able to affect 


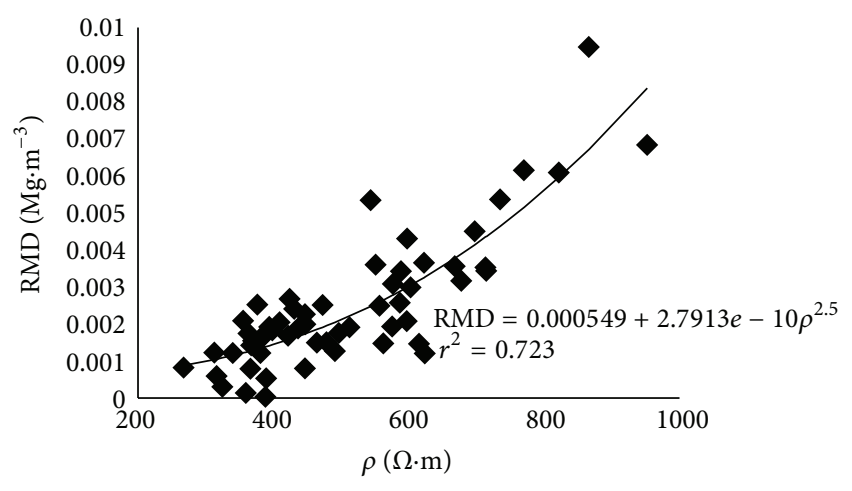

FIGURE 8: Root dry mass per unit soil volume (RMD) as a function of soil electrical resistivity $(\rho)$.

soil electrical resistivity, and this was quantitatively detectable, where root biomass yielded better correlation with $\rho$ than root length density [13].

However, the interpretation of the relationship between $\rho$ and RMD has to be carefully done. It can be ambiguous, and sometimes a site-specific calibration is necessary. It is well documented that several other factors such as nature and arrangements of solid constituents, soil water content, pore fluid composition, ionic solution, soil temperature, configuration of the electrodes in the survey, duration of the time of measurement, and contact between the soil and the electrodes can affect electrical resistivity [20].

In the context of soil sampling, electrical resistivity exhibits a large range of values from $1 \Omega \cdot \mathrm{m}$ for saline soil to a several $10^{5} \Omega \cdot \mathrm{m}$ for dry soil [11]. Furthermore, plant structures exhibit a range of $\rho$ values with water-filled conductive tissues at less $50 \Omega \cdot \mathrm{m}$ and resistive lignified parts at $10^{4} \Omega \cdot \mathrm{m}$ with means at $10^{2}$ to $10^{3} \Omega \cdot \mathrm{m}[23,24]$. Soil volumes colonized by roots showed high resistivities, ranging from 10 to $10^{2} \Omega \cdot \mathrm{m}$, in agreement with reported $\rho$ values for plant materials $[15,24]$. As a result, the ability to detect roots depends on the high $\rho$ values of roots compared with soil materials and other soil features $[12,22]$. So the $\rho$ values found in our research are in agreement with the values reported in the literature.

Root mass density (RMD) values are also in the same range of values found by other authors in annual and perennial plants. They reported RMD value in tree species ranging from 0.0015 to $0.21 \mathrm{Mg} \cdot \mathrm{m}^{-3}$ [12] and in alfalfa ranging from 0.00043 to $0.005 \mathrm{Mg} \cdot \mathrm{m}^{-3}$ [25] and in grasses values may increase from $0.0008 \mathrm{Mg} \cdot \mathrm{m}^{-3}$ to $0.001 \mathrm{Mg} \cdot \mathrm{m}^{-3}$ [7]. It was also related values of less than $0.0004 \mathrm{Mg} \cdot \mathrm{m}^{-3}$ in winter wheat [26] and $0.00092 \mathrm{Mg} \cdot \mathrm{m}^{-3}$ in alfalfa [13]. Considering the RMD values found in our research we can affirm that coffee trees root system was able to cause interference in soil electrical resistivity.

Soil water content, on the other hand, showed a nonlinear inverse relationship with $\rho$ in our research and presented a low $r^{2}$ value. Other inverse relationships with resistivity were found in the literature, and the amount of variability explained by soil water content in such studies is quite variable $[14,18,24,27]$. It can be attributed to several factors as mentioned before [20].

\section{Conclusions}

In our research we generated a high-resolution $2 \mathrm{D}$ geoelectrical tomography along a soil transect under plants in a coffee tree (Coffea arabica L.) stand and compared it with destructive soil sampling. The results showed that soil resistivity is quantitatively related to root biomass, and the technique provides a basis for nondestructive spatial detection of root mass in situ.

This preliminary study showed that the electrical resistivity tomography can contribute to root systems studies in coffee plants; however, considering the diversity of soils and conditions in which plants are cultivated in Brazil, more experiments are necessary to confirm the found results.

\section{Acknowledgment}

The author would like to express his gratitude to FapemigSectes for the financial support of this research.

\section{References}

[1] A. Fitter, "Characteristics and functions of root systems," in Plant Roots: The Hidden Half, Y. Waisel, A. Eshel, and U. Kafkai, Eds., p. 1002, Marcel Dekker, New York, NY, USA, 2nd edition, 1996.

[2] J. E. Box, "Modern methods for root investigation," in Plant Roots: The Hidden Half, Y. Waisel, A. Eshel, and U. Kafkai, Eds., p. 1002, Marcel Dekker, New York, NY, USA, 2nd edition, 1996.

[3] W. Bohm, Method of Studying Root Systems, Springer, New York, NY, USA, 1979.

[4] M. G. Johnson, D. T. Tingey, D. L. Phillips, and M. J. Storm, "Advancing fine root research with minirhizotrons," Environmental and Experimental Botany, vol. 45, no. 3, pp. 263-289, 2001.

[5] J. R. Butnor, J. A. Doolittle, K. H. Johnsen, L. Samuelson, T. Stokes, and L. Kress, "Utility of ground-penetrating radar as a root biomass survey tool in forest systems," Soil Science Society of America Journal, vol. 67, no. 5, pp. 1607-1615, 2003.

[6] J. R. Butnor, K. H. Johnsen, P. Wikström, T. Lundmark, and S. Linder, "Imaging tree roots with borehole radar," in Proceedings of the 11th International Conference on Ground Penetrating Radar, p. 8, Columbus, Ohio, USA, 2006.

[7] T. G. Chastain, W. C. Young III, C. J. Garbacik, and T. B. Silberstein, "Root productivity and seed production in grass crops," in Seed Production Research at Oregon State University, pp. 1518, USDA-ARS Cooperating, 1999.

[8] J. Hruska, J. Cermák, and S. Sustek, "Mapping tree root systems with ground-penetrating radar," Tree Physiology, vol. 19, no. 2, pp. 125-130, 1999.

[9] P. J. Gregory, D. J. Hutchinson, D. B. Read, P. M. Jenneson, W. B. Gilboy, and E. J. Morton, "Non-invasive imaging of roots with high-resolution x-ray micro-tomography," Plant and Soil, vol. 187, pp. 221-228, 2003.

[10] C. J. Moran, A. Pierret, and A. W. Stevenson, "X-ray absorption and phase contrast imaging to study the interplay between plant roots and soil structure," Plant and Soil, vol. 223, no. 1-2, pp. 99115,2000 
[11] G. J. Palacky, "Clay mapping using electromagnetic methods," First Break, vol. 5, no. 8, pp. 295-306, 1987.

[12] M. Amato, B. Basso, G. Celano, G. Bitella, G. Morelli, and R. Rossi, "In situ detection of tree root distribution and biomass by multi-electrode resistivity imaging," Tree Physiology, vol. 28, no. 10, pp. 1441-1448, 2008.

[13] M. Amato, G. Bitella, R. Rossi, J. A. Gómez, S. Lovelli, and J. J. F. Gomes, "Multi-electrode 3D resistivity imaging of alfalfa root zone," European Journal of Agronomy, vol. 31, no. 4, pp. 213-222, 2009.

[14] A. Loperte, A. Satriani, L. Lazzari et al., "2D and 3D high resolution geoelectrical tomography for non-destructive determination of the spatial variability of plant root distribution: laboratory experiments and field measurements," Geophysical Research Abstracts, vol. 8, p. 674, 2006.

[15] U. Weihs, V. Dubbel, F. Krummheuer, and A. Just, "The electrical resistivity tomography-a promising technique for detection of colored heartwood on standing beech trees," Forst Und Holz, vol. 54, pp. 166-170, 1999.

[16] D. L. Corwin and S. M. Lesch, "Apparent soil electrical conductivity measurements in agriculture," Computers and Electronics in Agriculture, vol. 46, no. 1-3, pp. 11-43, 2005.

[17] L. Lazzari, G. Celano, M. Amato et al., "Spatial variability of soil root zone properties using electrical imaging techniques in a peach orchard system," Geophysical Research Abstracts, vol. 10, p. 712, 2008.

[18] D. Michot, Y. Benderitter, A. Dorigny, B. Nicoullaud, D. King, and A. Tabbagh, "Spatial and temporal monitoring of soil water content with an irrigated corn crop cover using surface electrical resistivity tomography," Water Resources Research, vol. 39, no. 5, p. 1138, 2003.

[19] P. Kearey, M. Brooks, and I. Hill, An Introduction to Geophysical Exploration, Blackwell Science, Oxford, UK, 2002.

[20] A. Samouëlian, I. Cousin, A. Tabbagh, A. Bruand, and G. Richard, "Electrical resistivity survey in soil science: a review," Soil and Tillage Research, vol. 83, no. 2, pp. 173-193, 2005.

[21] G. Morelli and D. J. Labrecque, "Advances in ERT inverse modeling," European Journal of Environmental and Engineering Geophysics Society, vol. 1, no. 2, pp. 171-186, 1996.

[22] M. Amato and A. Pardo, "Root length and biomass losses during sample preparation with different screen mesh sizes," Plant and Soil, vol. 161, no. 2, pp. 299-303, 1994.

[23] S. A. Al Hagrey, "Electrical resistivity imaging of tree trunks," Near Surface Geophysics, vol. 4, no. 3, pp. 179-187, 2006.

[24] S. A. Al Hagrey, "Geophysical imaging of root-zone, trunk, and moisture heterogeneity," Journal of Experimental Botany, vol. 58, no. 4, pp. 839-854, 2007.

[25] L. V. Vaughan, J. W. Macadam, S. E. Smith, and L. M. Dudley, "Root growth and yield of differing alfalfa rooting populations under increasing salinity and zero leaching," Crop Science, vol. 42, no. 6, pp. 2064-2071, 2002.

[26] A. R. Barzegar, M. H. Mossavi, M. A. Asoodar, and S. J. Herbert, "Root mass distribution of winter wheat as influenced by different tillage systems in semi arid region," Journal of Agronomy, vol. 3, no. 3, pp. 223-228, 2004.

[27] G. E. Archie, "The electrical resistivity log as an aid in determining some reservoir characteristics," Transactions of American Institute of Mining Engineers, vol. 146, pp. 54-61, 1942. 

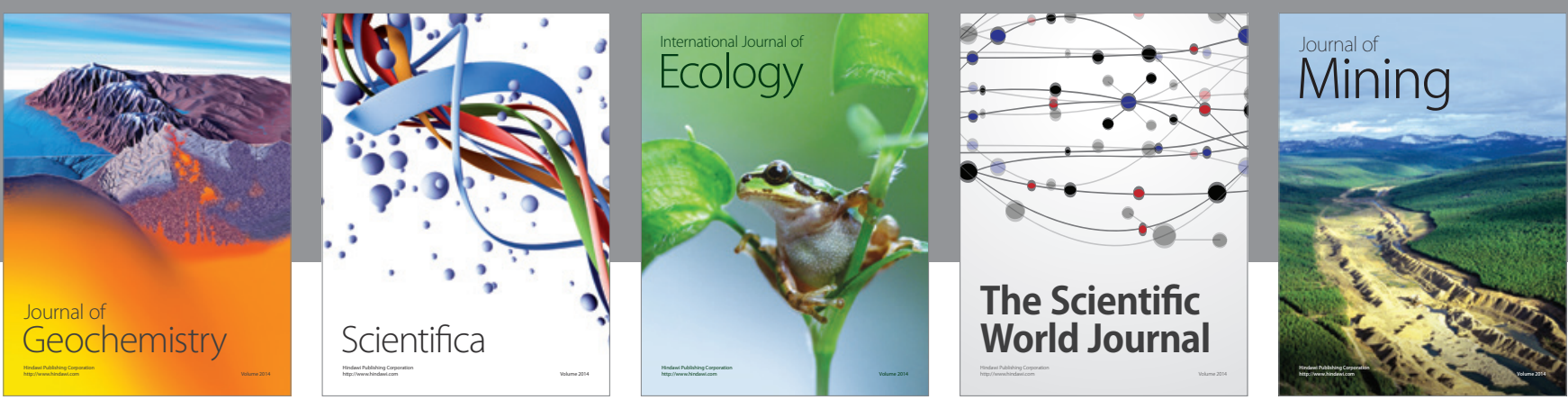

The Scientific World Journal
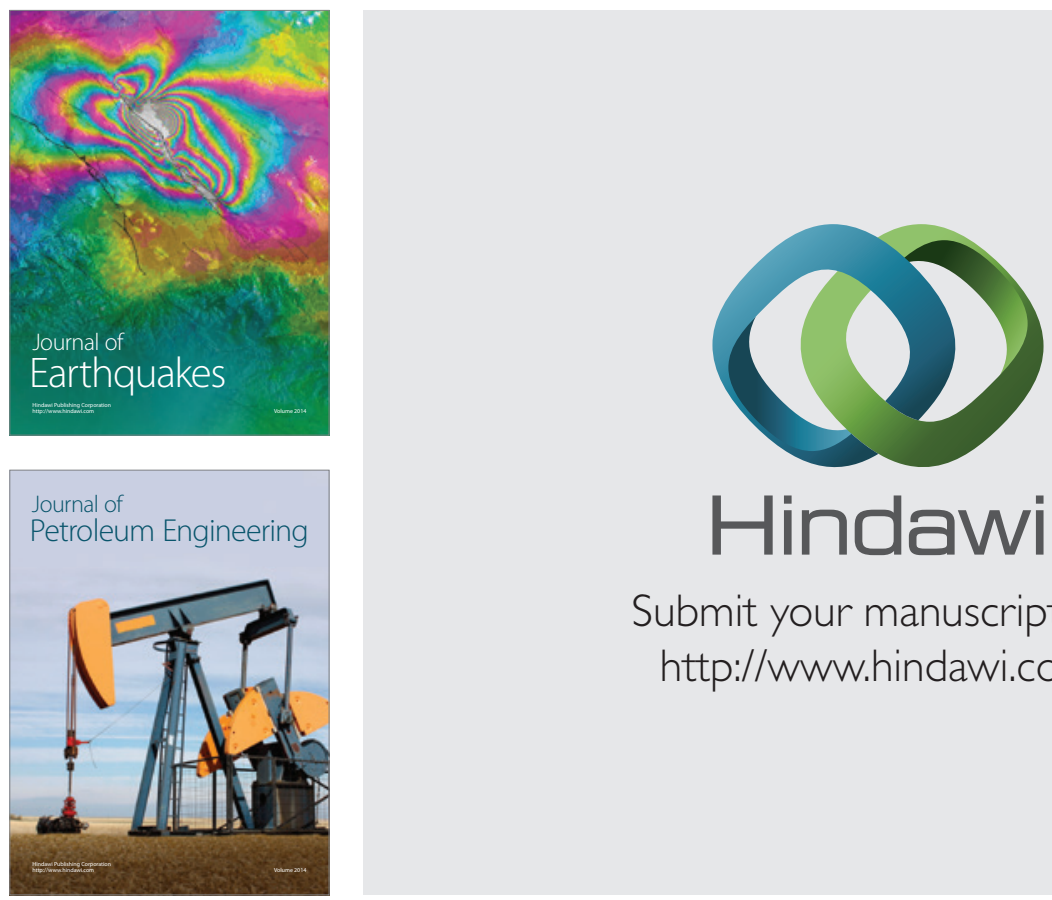

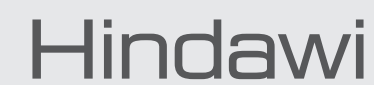

Submit your manuscripts at

http://www.hindawi.com
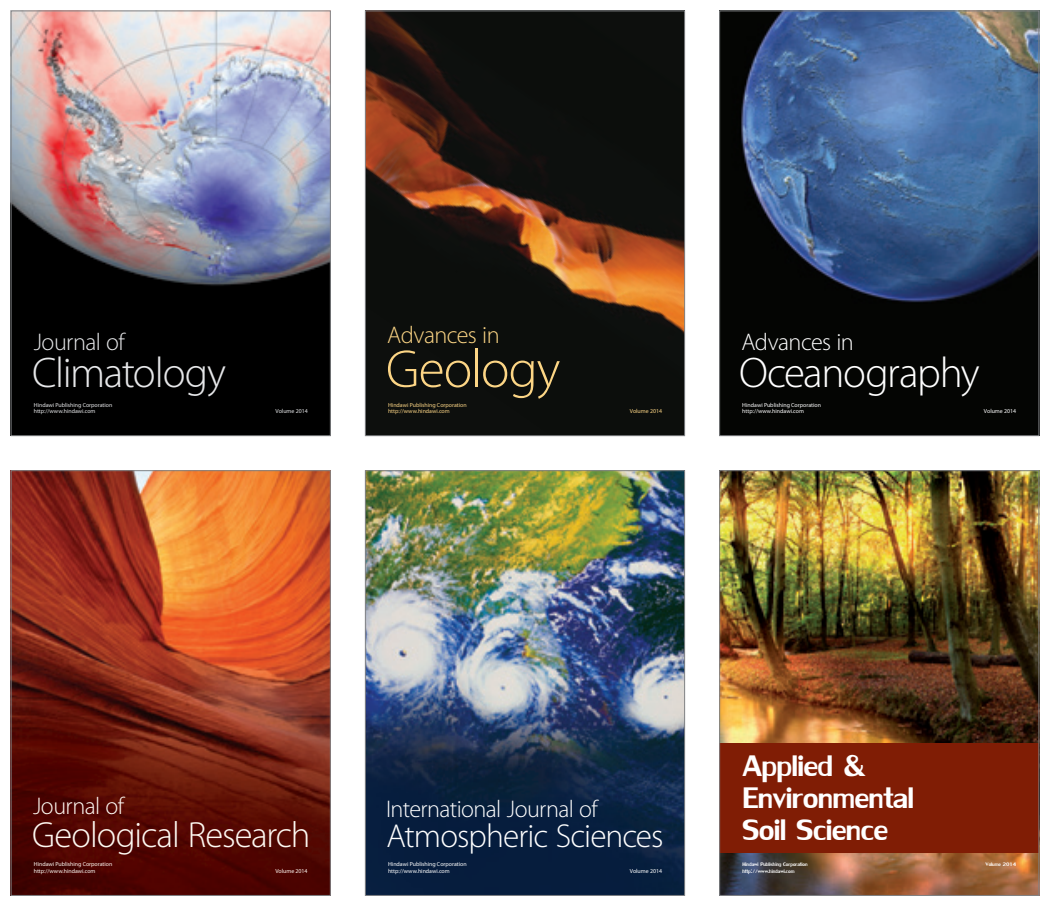
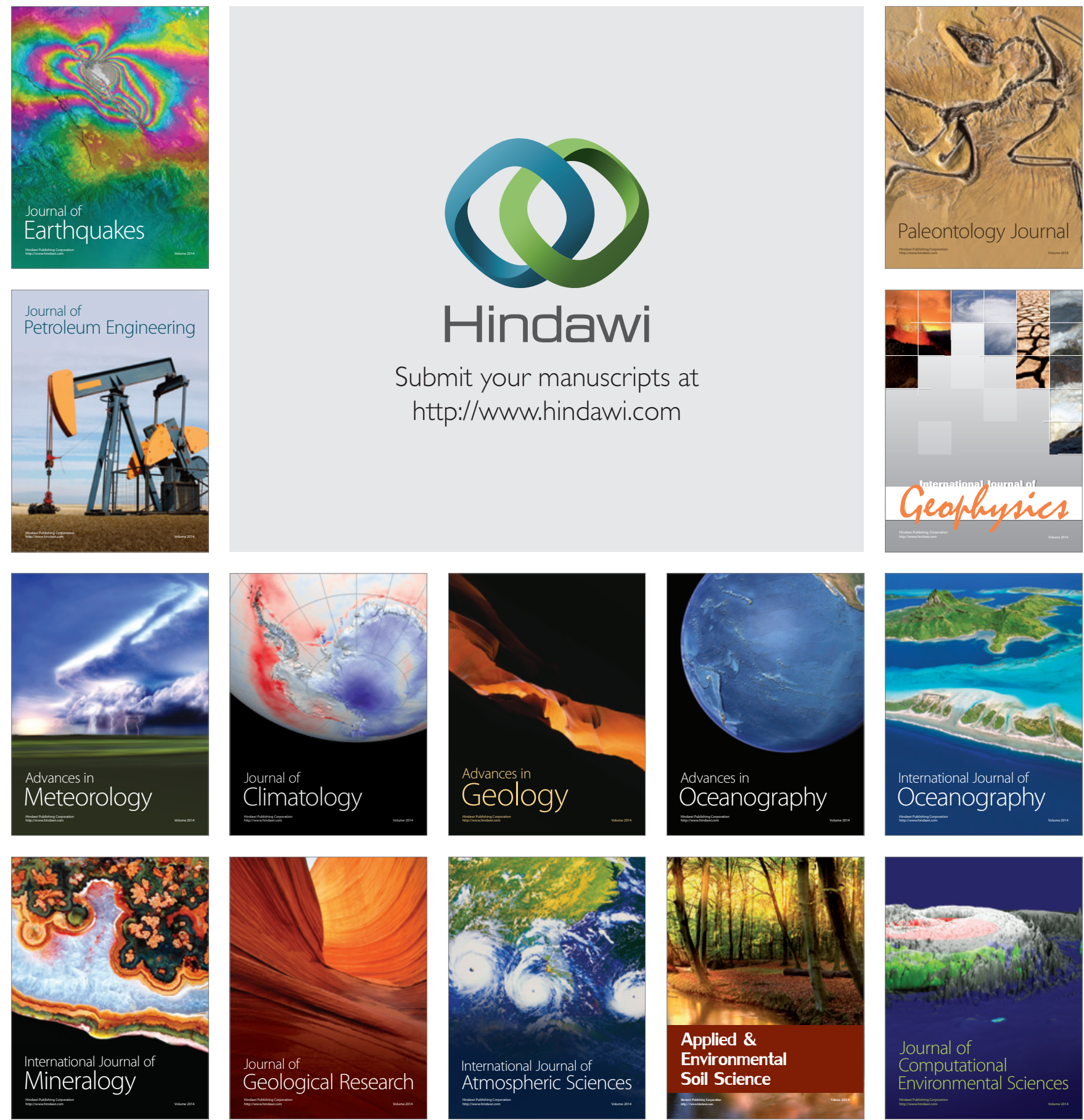